\title{
Ensuring safe drinking water in regional NSW: the role of regulation
}

\author{
Paul M. Byleveld ${ }^{\mathrm{A}, \mathrm{D}}$, Michelle A. Cretikos ${ }^{\mathrm{B}, \mathrm{C}}$, \\ Sandy D. Leask ${ }^{\mathrm{A}}$ and David N. Durrheim ${ }^{\mathrm{C}}$ \\ A Water Unit, NSW Department of Health \\ ${ }^{\mathrm{B}}$ NSW Public Health Officer Training Program, NSW Department \\ of Health \\ ${ }^{\mathrm{C}}$ Hunter New England Population Health, Hunter New England \\ Area Health Service \\ DCorresponding author. Email: paul.byleveld@doh.health.nsw.gov.au
}

acute outbreaks of waterborne gastrointestinal disease. Illness related to unsafe drinking water can lead to substantial morbidity and mortality, community anger and detrimental economic impacts. ${ }^{1,2}$

NSW Health exercises its responsibility as the public health regulator of metropolitan water utilities (Sydney Water Corporation, Sydney Catchment Authority and Hunter Water Corporation) through operating licences and memoranda of understanding. In regional and rural areas of NSW, drinking water is provided by 107 local water utilities, mostly councils, serving a population of 1.7 million and operating 323 public water supply systems. NSW Health provides public health oversight of these regional water utilities through the NSW Health Drinking Water Monitoring Program. ${ }^{3}$ The Drinking Water Monitoring Program provides guidance on drinking water monitoring as well as on implementing several elements of the Australian Drinking Water Guidelines. ${ }^{4}$ This paper describes the Program and its regulatory context and reviews the impact of the Program on microbial drinking water quality.

\section{The Australian Drinking Water Guidelines}

The Australian Drinking Water Guidelines published by the National Health and Medical Research Council serve as the model of best practice in NSW. ${ }^{4}$ These guidelines provide a risk management framework for drinking water supply systems, which includes a multiple barrier 'catchment to tap' approach, because a single barrier risk management approach is vulnerable to failure. ${ }^{5}$ The Guidelines recommend that systems should be monitored for drinking water quality and operational compliance. ${ }^{4}$

The Guidelines provide guideline values for microbial, physical, chemical and radiological characteristics that affect health or the quality of drinking water, and recommend that drinking water supplies be monitored regularly for Escherichia coli, which is an indicator of faecal contamination.

Although monitoring is an important step in verifying that preventive measures are working effectively, the current monitoring system for NSW regional water supplies has a number of inherent limitations, including:

- sampling cannot detect all contamination events

- exposure of the supply population to contaminated water may occur days before a non-compliant sampling result is available
Safe drinking water is essential for public health. Drinking water can pose serious health risks through microbial and chemical contamination, or inadequate disinfection and treatment. ${ }^{1,2}$ In particular, microbial contamination poses an ongoing threat of sporadic gastrointestinal illness and 
- the system may fail to identify contamination with certain pathogens (e.g. protozoa or viruses) unless the contamination is accompanied by the indicator organism (E. coli) or elevated turbidity.

Thus the current system of microbial and chemical monitoring of regional water supplies is unable to provide routine early warning of contamination events. For water utilities to supply drinking water that is safe, as defined in the Guidelines, NSW Health strongly recommends that water utilities implement the Guideline's Framework for Management of Drinking Water Quality.

\section{The legislative basis for ensuring drinking water safety}

In 1998, Sydney's drinking water was found to contain Cryptosporidium and Giardia, which resulted in a series of alerts to boil water affecting more than three million consumers over a two-month period. Following this event, the Public Health Act 1991 was amended to ensure that NSW Health had adequate powers in relation to drinking water quality. ${ }^{6,7}$ The amendments gave NSW Health the powers to:

- require a water utility to issue advice to the public regarding the safety of drinking water (e.g. a boil water alert)

- correct misleading information issued by a water utility

- enter and inspect water utility premises

- require the testing of drinking water

- require the production of information (e.g. the results of water testing)

- close a water supply or order that it be brought to a condition that no longer poses a risk to public health.

In contrast to the operating licence requirements for metropolitan water utilities, there is no requirement for regional water utilities to fully implement the Australian Drinking Water Guidelines (and its framework).

\section{How does NSW Health exercise its legislative responsibility?}

The current NSW Health Drinking Water Monitoring Program has been operating comprehensively since 2001 . Samples are allocated annually to each public water supply system and tested by NSW Health (or other accredited) laboratories free of charge. Characteristics routinely tested include microbial (E. coli, total coliforms and corresponding field results, including chlorine) and physical/ inorganic chemical (more than 30 characteristics). Characteristics tested through project monitoring include bacterial pathogens, pesticides and disinfection by-products (more than 150 characteristics). Microbial and physical/ chemical monitoring results are stored in the internetbased NSW Drinking Water Database, which allows secure access to results for local water utilities, NSW Health and other government agencies. ${ }^{8}$ The Database records results for more than 20000 samples per year from 323 water supply systems. The Database has a user-friendly web interface that allows water utilities and public health units to search for results, generate reports and download data files (Figure 1). The reports provide basic descriptive statistics for each characteristic, including the number of samples tested and the percentage of samples meeting guideline values.

The NSW Health Drinking Water Monitoring Program meets the recommendations of the World Health Organization by providing public health oversight of drinking water supplies, using predominantly independent testing and consolidating data as an input to the development of public health policies. ${ }^{9}$

The Program recommends the minimum numbers of samples that should be taken based on the size and complexity of water supply systems and in accordance with the Guidelines. This allocated number of samples must be collected to ensure that water quality remains satisfactory. The Program provides water utilities with protocols for responding to incidents of contamination (both microbial and chemical) or treatment system interruption. The Program also defines the roles of the NSW Department of Health Water Unit, local public health units and the local water utility in responding to such incidents.

Significant factors in the acceptance of the current Program include its development in consultation with, and support by, the peak industry bodies, including Local Government and Shires Associations and the NSW Water Directorate.

\section{Functioning of the NSW Health Drinking Water Monitoring Program}

The current Program commenced in late 2000, with data captured from 2001. The Water Unit and local public health units are active in promoting the Program to local water utilities. Multiple methods of communication are used to ensure the widest possible understanding of the Program within water utilities.

Each year, the Water Unit writes to the water utility general managers to advise them of sampling frequency recommendations. Sample testing is provided free of charge by NSW Health laboratories. The Water Unit issues bar-coded labels that uniquely identify each sample collected under the Program and remove the need for sample submission forms, previously completed by water utilities. NSW Health also actively promotes the Program through industry conferences, newsletters and regional training workshops for local water utilities. The Department of Water and Energy (DWE) has supported and promoted the Program through their Best-Practice Management of Water Supply and Sewerage Guidelines and training courses for water treatment plant operators. 


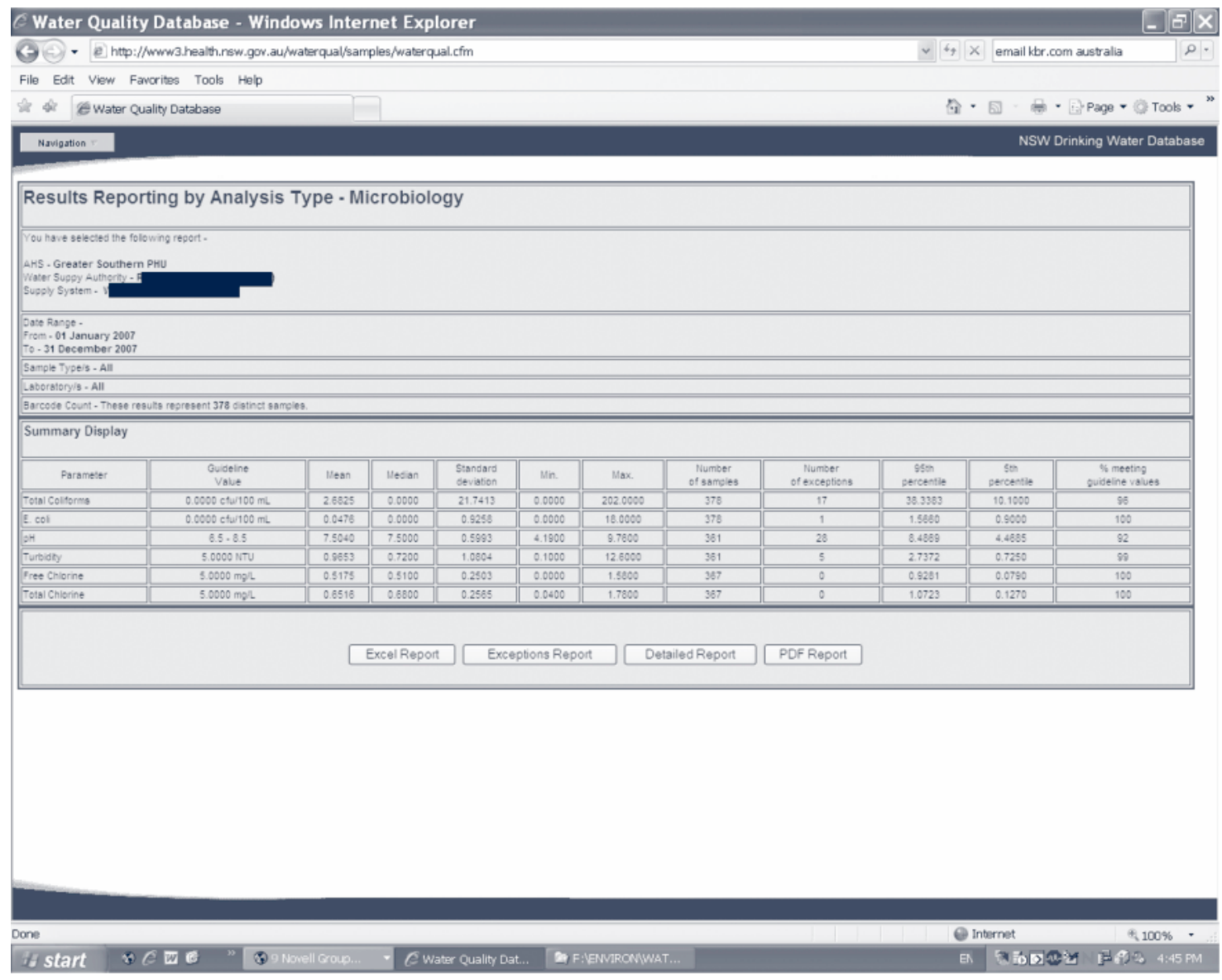

Figure 1. A screen view of the NSW Drinking Water Database.

NSW Health and the DWE actively encourage water utilities to adopt the Framework as a model for managing their supplies. However, it is unlikely that all regional water utilities will fully implement the Framework unless it becomes a regulatory requirement.

Some water utilities use the Database results to prepare reports for local communities. The Database also allows NSW Health to monitor the adequacy of sampling and reporting by each utility. Reminders are issued to utilities to increase sampling frequency where needed.

NSW Health laboratories report non-compliant results to the water utility and public health unit. This provides public health units with an opportunity to confirm that the response protocols are being followed, including investigation and immediate corrective action by the local water utility.

\section{The impact of the NSW Health Drinking Water Monitoring Program}

The current Program has helped improve the management of regional and rural water supplies. Prior to its introduction, $10 \%$ of microbial samples were reported to be noncompliant, and $27 \%$ of water supply systems failed to submit samples. ${ }^{10}$
Since the introduction of the current Program, there has been a significant improvement in both microbial compliance (Figure 2) and adequacy of microbial sampling (Figure 3) in regional NSW. The significance of improvement was assessed using the Cochran-Armitage test for trend in compliance by year. In 2007, the overall results of microbial sampling achieved the Australian Drinking Water Guidelines 2004 criteria, i.e. no more than two samples per 100 samples were non-compliant for $E$. coli (Figure 2). This improvement appears to be the result of many factors, including improved reporting to the NSW Health Drinking Water Monitoring Program, monitoring and maintenance of regional drinking water systems, disinfection and treatment of drinking water supplies, and sampling frequency. It is possible that in some systems there are sampling biases that result in unusually high compliance. Despite the improvements in regional microbial performance, some small water supply systems remained well below the targets for sampling frequency and water quality. In order to better detect systematic problems, repeat testing and follow up occurs with water utilities that have non-compliant samples, especially with those that exceed the $2 \%$ target.

The NSW Health Drinking Water Monitoring Program and the Database has been well accepted by local water utilities 


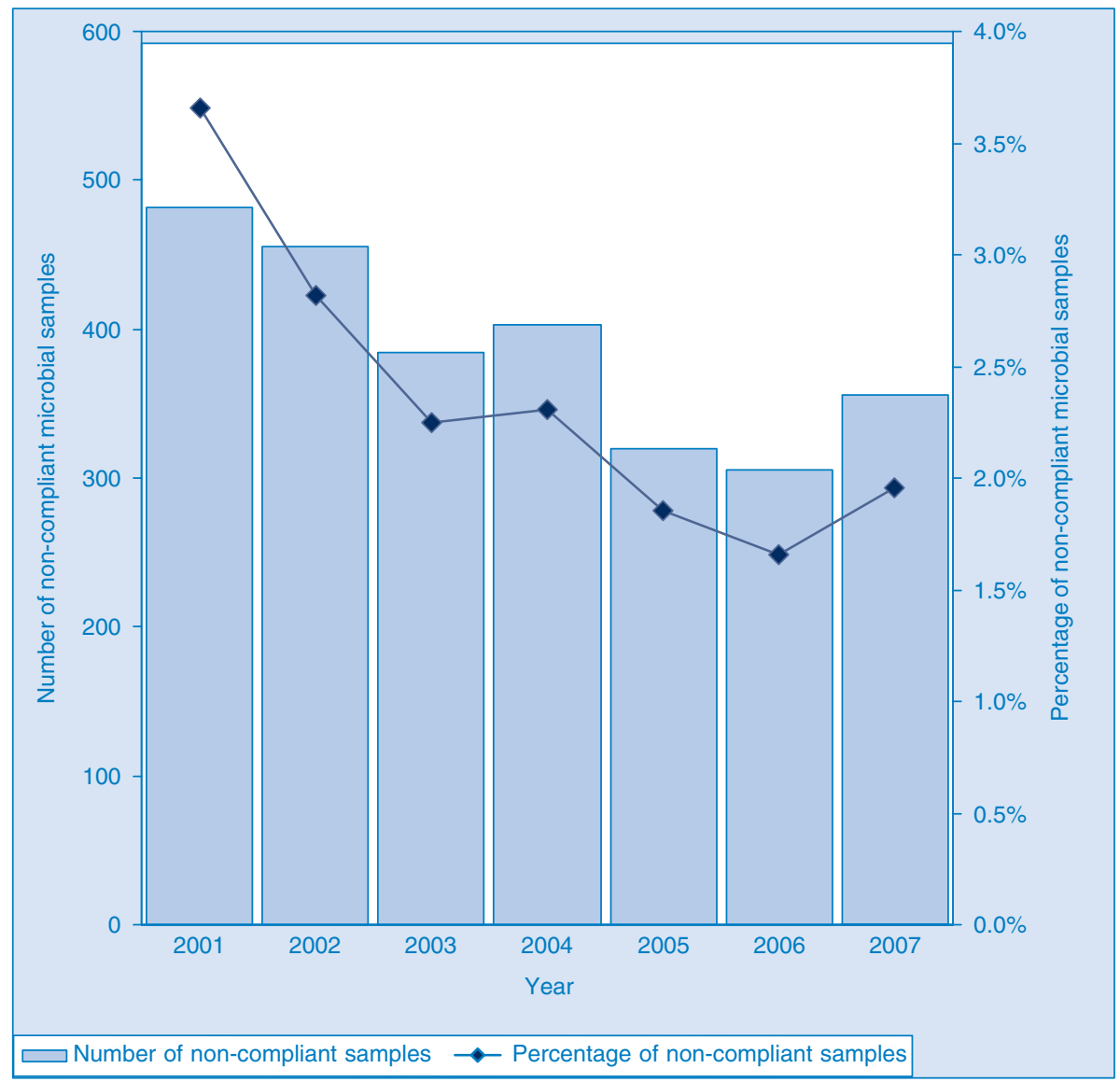

Figure 2. Trend in microbial compliance in regional NSW by year (2001-2007), samples tested for Escherichia coli. $p$ value $<0.001$ for trend test (Cochran-Armitage test). Source: NSW Drinking Water Database.

and government agencies. Since the amendment of the Public Health Act in 1998, NSW Health has not used legislative powers to place orders on public water utilities. In contrast, over the same period, orders have been placed on two private water supplies that represented a risk to public health and did not comply with NSW Health advice.

The powers would be used in relation to water utilities should it be necessary. To make such decisions, public health units have access to the Database and disease surveillance data. In cases where a water utility does not meet sampling requirements, public health units follow up and remind the water utility of the requirements and the powers that exist under the Public Health Act. Where a persistent risk to public health is identified, the public health unit will advise the water utility to issue an alert to boil water or other warnings to the community. In most cases, water utilities willingly issue alerts to boil water, often before public health unit intervention.

During 2007, there were 12 such alerts issued in regional NSW. Two of these alerts were instituted before test results became available, and were the result of contaminated raw water or treatment failure. The remainder were issued following the detection of $E$. coli in routine drinking water samples. In such cases, the community may already have been exposed by the time a boil water alert is issued. Complete implementation of the Guideline's Framework for Management of Drinking Water Quality by all water utilities is the only way to ensure safe drinking water for regional communities.

\section{Conclusion}

The NSW Health Drinking Water Monitoring Program has contributed to a marked improvement in the monitoring and quality of drinking water in regional NSW. This has been achieved through a combination of factors, including: a clear regulatory framework; a centralised system of ongoing sampling monitoring; technical support for local utilities and public health units; and collaborative relationships between public health units and local water utilities. Despite these improvements, more work is needed to support smaller water supply systems to meet the Australian Drinking Water Guidelines requirements and ensure safe drinking water for their communities. 


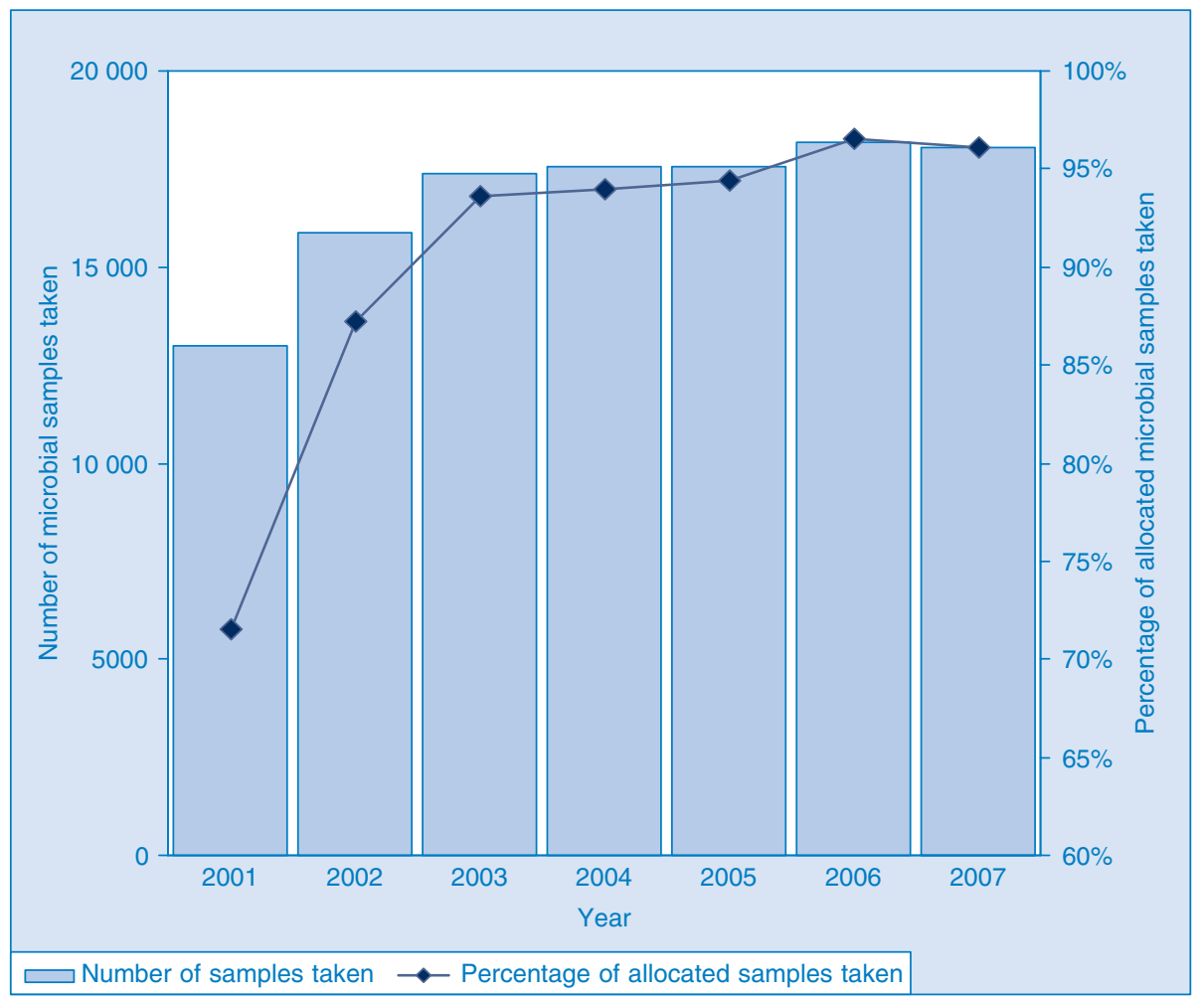

Figure 3. Trend in microbial sampling adequacy in regional NSW by year (2001-2007), using samples tested for either Escherichia coli or thermotolerant coliforms. p value $<0.001$ for trend test (Cochran-Armitage test). Source: NSW Drinking Water Database.

The NSW Drinking Water Database has helped identify persistent and sporadic problems in water supplies. It has also provided useful historical data to inform decision making on improvements required for specific supplies. Access to this data has proven useful in advocating for upgrades to water treatment, prioritising expenditure under the Country Towns Water Supply and Sewerage Program, and informing government inquiries.

The most significant challenge for the future is to ensure that all water utilities fully implement the Australian Drinking Water Guidelines Framework. Communities cannot simply rely on end-point drinking water quality monitoring to prevent outbreaks. There is strong international consensus that a preventive risk-management approach as set out in the Framework is the most reliable way to protect public health.

\section{Acknowledgment}

Thanks to Ling Li for preparing the figures.

\section{References}

1. Hrudey SE, Hrudey EJ. Safe drinking water: lessons from recent outbreaks in affluent nations. London, UK: International Water Association Publishing; 2004.

2. Hunter PR, Waite M, Ronchi E, eds. Drinking water and infectious disease: Establishing the links. Boca Raton, Florida: CRC Press/IWA Publishing; 2003.
3. NSW Health. Drinking Water Monitoring Program December 2005. NSW Department of Health; 2008.

4. National Health and Medical Research Council and Natural Resource Management Ministerial Council. Australian Drinking Water Guidelines. Canberra: NHMRC; 2004.

5. Reason J. Managing the risk of organisational accidents. Aldershot, UK: Ashgate; 1997.

6. McClellan P. Sydney Water Inquiry - Final Report Volumes 1 and 2. Sydney: New South Wales Premier's Department; 1998.

7. NSW Public Health Act 1991 No 10.

8. Persson L, Byleveld P, Fien M, Cowie C. NSW Drinking Water Database. Perth: OzWater Australian Water Association National Convention, April 2003, pp. 60-1.

9. World Health Organization. Guidelines for drinking-water quality [electronic resource]: incorporating first addendum. Vol. 1, Recommendations, 3rd ed. Geneva: WHO; 2006. Available at: http://www.who.int/water_sanitation_health/dwq/gdwq3rev/en/ (Cited 23 October 2008.)

10. Cowie C, Corbett S. Surveillance of rural drinking water quality in NSW. N S W Public Health Bull 1994; 5: 35-9. doi:10.1071/NB94016 